У, $\triangle \mathrm{K} 342.7$

ББК 67.400 .3

DOI 10.22394/1682-2358-2019-3-10-18

O.V. Lisina, lecturer of the Administrative and Criminal Law Department, post-graduate student of the Service and Labor Law Department, Povolzbsky Institute of Management named after P.A. Stolypin, Branch of the Russian Presidential Academy of National Economy and Public Administration

\section{CONSTITUTIONAL RESTRICTION \\ OF HUMAN \\ AND CIVIL RIGHTS AND FREEDOMS: CONCEPT AND LIMITS}

The issue of legal substantiation of the constitutional restriction of human and civil rights and freedoms is analyzed. The concept and essence of restriction of human and civil rights and freedoms are considered, and its essential features, such as principles, basis, goals, limits and the legal form of consolidation, are investigated.

Key words and word-combinations: human rights and freedoms, the concept of constitutional limitations of rights and freedoms, the constitutional limits of restrictions of rights and freedoms.
O.B. Мисина, преподаватель кафедри административного и уголовного права, аспирант кафедры служебного и трудового права Поволжского института упраһления имени П.А. Стольгпина - филиала Российской академии народного хозяйства и государственной службь при Президенme РФ (email: lisina-o-64@yandex.ru)

\section{КОНСТИТУЩИОННОЕ ОГРАНИЧЕНИЕ ПРАВ И СВОБОА ЧЕ $А$ ОВЕКА И ГРАЖКААНИНА:

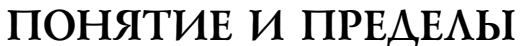

\footnotetext{
Аннотация. Анализируется проблема юридического обоснования конституционного ограничения прав и свобод человека и гражданина. Рассматриваются понятие и сущность ограничения прав и свобод человека и гражданина, исследуются его существенные признаки: принципы, основания, цели, пределы и правовая форма закрепления.

Ключевые слова и словосочетания: права и свободы человека, понятие конституционных ограничений прав и свобод, пределы конституционных ограничений прав и свобод.
}

Ж щества невозможно представить без правового регулирования. Государство в целях упорядочения общественных отношений при помощи юридических средств регламентирует проџедуру реацизации гражданами прав и свобод, а также предусматривает возможность их ограничения. В научных 
кругах проблема правового ограничения прав и свобод обсуждается достаточно давно, но ее концептуальное решение так и не найдено, что препятствует пониманию особенностей взаимодействия мичности, общества и государства, повышению качества нормотворчества и эффективности применения законов, а также осуществлению гражданами конституџионно провозглашенных прав и свобод. ЯАром дискуссии явмяются понятие и пределы такого ограничения. В связи с этим исследуются вопросы о его природе и сущности, основаниях, принципах, цемях (критериях), границах, механизмах регулирования и Аругие. Отсутствие единообразно интерпретируемого понятия привело к разАичному пониманию его содержания, структурного наполнения и самого соџиально-правового феномена, отразившегося в нем.

Анализ понятия «ограничение» и обоснованность пределов его законоАательного закрепления требует раскрытия содержания основополагающих взаимосвязанных категорий «права» и «свободы», которые одними исследователями отождествцяются [1, с. 7], а, по мнению других, все же имеют неравное содержание [2, с. 21]. Конкретизация этих явлений определяет наличие или отсутствие потенциальной возможности их ограничения государственной вАастью.

Н.И. Матузов, исследуя теорию и практику прав человека, терминологически не разделял конституџионно закрепленные «права и свободы», признавая наряду с Аругими характеризующими особенностями их прирожденность и неотчужАаемость. Ученый рассматривац «права и свободы» в качестве субъективных прав граждан, отмечая, что «субъективно-притязательный характер имеют не только гражданские, имущественные, социально-экономические права, но и политические и мичные сбободь (курсив наш. - О.А.): слова, печати, собраний, митингов, уличных шествий, демонстраций, мнений, убеждений, совести и т.А.» [3, с. 26], соглашаясь с Б.А. Кистяковским в том, что «...им преимушественно присущи особые индивидуализация и связь с мичностью...» [4, с. 499]. Такое утверждение подталкивает к мысли о разАичных сущностных характеристиках «прав» и «свобод».

Аействительно, В.И. Ааль право определял как дарованные человеку власть и воля в допускаемых пределах, в то время как свобода есть «своя воля, простор, возможность действовать по-своему; отсутствие стесненья, неволи, рабства, подчинения чужой воле. Свобода понятие сравнительное; она может относиться до простора частного, ограниченного, к известному делу относящийся, или к разным степеням этого простора, и наконещ к полному, необузАанному произволу или самовольству» [5, с. 156].

При сопоставлении с правом свобода представмяет собой более абстрактное, скорее философское, понятие, поскольку явмяется естественным состоянием каждого человека, с которым он приходит в этот мир. В идеальном воплощении - это возможность делать что хочется на свой выбор. Только сам человек может распоряжаться своей свободой - жить или не жить, труАиться или быть тунеядџем, подАерживать свое здоровье или губить его и т.А. Подтверждение этому можно найти и в некоторых положениях Конститущии Российской Федераџии: «Никто не может быть без добровольного согласия 
(курсив наш. - О.А.) подвергнут медицинским, научным или иным опытам» (ст. 21); «Сбор, хранение, использование и распространение информаџии о частной жкизни киџа без его согласия (курсив наш. - О.А.) не Аопускается» (ст. 24) [6]. Можно ПреАПоложкить, что свобода сродни всеАозволенности, однако это не так, поскольку в ее основе всегда цежат морацьные устои и нравственно-этические ценности мичности, удерживающие от неодобрительного поведения. ЗАесь возникает вопрос о средствах обеспечения реализации свободы каждого человека в обществе и государстве. Нередко, как известно, побеждает сильный (государство), а свобода слабого (человека) ущемлена. Во избежание такого неравенства необходимо урегулировать их взаимоотноше-

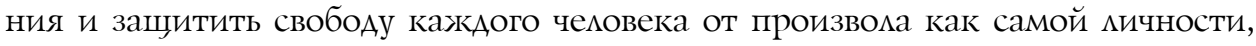
так и государства.

Указанным регулятором небезосновательно можно считать право в цемом и конституџионно-правовые нормы в частности. Так, Т.Я. Хабриева и В.Е. Чиркин считают, что «право есть мера реацизации свободы... Оно покоится на идее справедиивости» [7, с. 6]. Исходя из данного утверждения, можно заключить, что право устанавливает определенные граниџы свободного волеизъявления человека, в рамках которых он вступает в отношения с Аругими цюдьми и с государством, а также явцяется ограничителем государственной вцасти. Таким образом, естественная свобода в некотором смысле ограничивается сушествованием самого права, что неизбежно в гражданском обществе и правовом государстве. В то же время право не затрагивает ценностную сущность свободы, не мишает и никоим образом не умаляет ее, оно организует поведение человека, основываясь на принџипе «разрешено все, что не запрещено законом», констатируя необходимость признания и уважения свободы Аругих Аиџ.

Конститущия РФ, декларируя приоритет защиты человека, провозглашает высшей ценностью его права и свободы (ст. 2), используя именно словосочетание «права и свободы». Значит ми это, что в Основном Законе указанные понятия дифференцированы? ПреАставцяется, что они обозначают целостное явление, охватывающее признание государством естественной свободы человека наряду с конституционно закрепленными правами, и понимание, что свободное проявление воли как таковое есть непосредственный источник

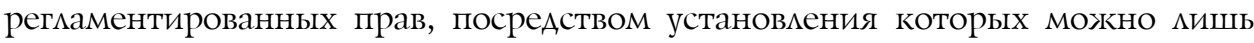
скорректировать путь ее реализаџии. Так, свобода жкить, иметь семью, использовать свои таланты, способности ици возможности Аля какой- ибо правомерной деятельности или Аругие не исчезнут в зависимости от наличия или отсутствия их правового регулирования. Межау тем без признания государством перечисленные блага остаются незащищенными, что существенно затрудняет их использование. С признанием - государство берет на себя обязательство по их охране, что позвоцяет кажкому гражданину, избравшему законопослуш-

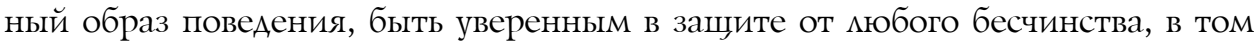
числе государственно-властного.

Положения Конституџии РФ фиксируют значимость основных свобод чемовека, представцяя собой юридический фунАамент, сформированный из кич- 
ных, социальных, политических, имущественных, экономических, культурных прав человека и гражданина, обеспечивающих и гарантирующих их (свобод) реализаџию. Например, С.А. Авакьян, рассуждая о свободе общественного мнения, приводит несколько конституционных норм, закрепленных в ст. 1, 2, 13, 29-33, которые служкат ее правовой опорой [8, с. 6-8] и, соответственно, надецяют субъектов соответствующими правами Аця беспрепятственного ее воплощения. Таким образом, категории «права» и «свободы» по содержанию и форме выражкения не тождественны, однако находятся во взаимосвязи, взаимообусловленности и диалектическом единстве.

Как упоминалось, свобода человека не может быть ограничена по своему существу. А можно ми ограничить конституционное право человека, являющееся одним из элементов правового статуса иичности? Слово «ограничение» относительно прав и свобод человека и гражданина встречается в Основном Законе восемь раз. Основополагающим в Аанном контексте является положение ч. 3 ст. 55 Конституции РФ, прямо указывающее: «Права и свободы человека и гражданина могут быть ограничены федеральным законом только в той мере, в какой это необходимо в целях защиты основ конститущионного

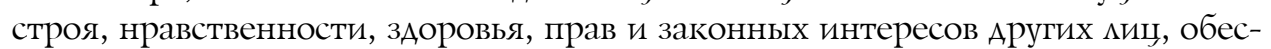
печения обороны страны и безопасности государства».

Следует отметить, что возможность ограничения прав и свобод человека существует не только в российском правовом пространстве, но и закреплена в общепризнанных принципах и нормах международного права (Всеобщая декларация прав человека, Международный пакт об экономических, социацьных и культурных правах, Международный пакт о гражданских и политических правах, Конвенция о защите прав человека и основных свобод и др.), а также конститущиях иностранных государств. Не вдаваясь в подробности сопоставцения наџионацьного и международного законодательства, выделим из них правовые ограничения: общего характера; в условиях чрезвычайного (военного) положения; применяемые в отношении отдельных категорий миџ (военнослужащие, миџа, находящиеся под уголовным преследованием, осужленные к уголовным наказаниям и др.). Они проявляются по-разному и имеют разАичные основания: могут происходить из нормативно-правового акта ици вытекать из фактических действий; могут быть установлены на постоянной или временной основе. Объединяет их то, что мюбые ограничения в той ими иной степени затрагивают конституџионно-правовой статус Аичности.

Ученые интерпретируют правовой феномен «ограничение прав и свобод» исходя из собственного исследовательского опыта и восприятия. «Ограничивая свободу каждого известными пределами, право обеспечивает ему беспрепятственное и спокойное пользование своими правами, т.е. гарантирует ему

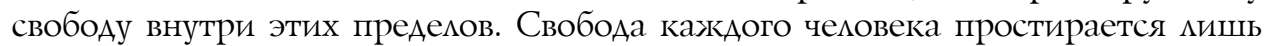
Ао той границы, от которой начинается - свобода других Аюдей. Стремясь установить эти граниџы, право содействует тому, чтобы в совместной жизни мюдей воцарился порядок, основанный на свободе», - писал И.А. Имьин [9, с. 96]. По мнению К. Хессе, правовые ограничения - это «установценные в 
праве границы, в пределах которых субъекты должны действовать; это есть сдерживание неправомерного поведения, создающее условия Аля удовлетворения интересов контрагента (в широком смысле слова) и общественных интересов в охране и защите» [10, с. 163]. Ведущим исследователем ограничений в праве А.В. Малько сформулировано более полное определение рассматриваемого явления: «...правовое сдерживание противозаконного Аеяния, создающее условия Аля удовлетворения интересов контрсубъекта и общественных интересов в охране и защите; это установленные в праве граниџы, в пределах которых субъекты должны действовать; исключение определенных возможностей в деятельности миџ» [11, с. 142] .

Чтобы осмыслить мюбое понятие, необходимо выделить его существенные признаки. Из перечисленных утверждений обращают на себя внимание повторяемые словоформы: «пределы», «границы», «дия уАовлетворения интересов», которые, собственно, и характеризуют эмементы содержания правового ограничения как социально-правового явления: во-первых, установление рамок поведения человека, влекущее количественное уменьшение объема его прав и свобод; во-вторых, обусловленность наличием цели.

Возвращаясь к конституционно-правовому закреплению рассматриваемого явления (ч. 3 ст. 55), отметим, что оно также содержит указание на возможность воздействия на права и свободы человека и гражАанина посреАством определения граниџ и цели, уточнив при этом, что ограничения должны быть соразмерны вызвавшим их необходимым обстоятельствам и облечены в форму федерального закона.

Выявленные признаки имеют оџеночный, абстрактный характер - ими не определено, насколько могут быть ограничены права и свободы, не регламентированы критерии соразмерности, не отражено соответствие Аругим правовым принципам и другое. Опасность такой неопределенности заключается в потенциацьной необоснованности их применения.

Во взаимосвязи с исследованием проблемы воздействия ограничительных мер на существо прав и свобод в научной среде активно обсуждается вопрос соотношения конституционно-правовых дефиниџий: «отмена», «умаление» и «ограничение» прав и свобод человека и гражданина. Аискуссия вызвана предполагаемым противоречием межАу ч. 2 ст. 55 Конституции РФ, предусматривающей запрет на издание законов, отменяющих или умаляющих права и свободы человека и гражданина и ч. 3 ст. 55 Конститущии РФ, то есть ч. 2 ст. 55 не позволяет ущемлять права и свободы, а ч. 3 ст. 55 - напротив. Безусловно, ограничение прав и свобод Аля Аостижения конституционно значимых целей нельзя рассматривать как их умаление, поскольку оно предполагает сужение количественных, а не качественных характеристик [12, с. 20]. Сложкно преАставить, что прирожденные, неотчуждаемые права и свободы можно деформировать при помощи правовых средств, если не говорить о полной их отмене (например, снятие моратория на смертную казнь), ведь они имманентно присущи человеку независимо от признания государством и закрепления в законе. Вероятнее предположить, что законодательное ограничение способно изменить

\section{Bulletin of the Volga Region Institute of Administration • 2019. Vol. 19. № 3}


правика реализаџии ици, в худшем случае, запретить использование прав и свобод на какой-то период времени. В связи с этим целесообразным преАставцяется суждение М.А. Краснова о том, что «... ограничения Аопустимы и даже необходимы. Но только при реализации праљ (курсив наш. - О.А.) на основании конституционно и законодательно установленных условий и порядка» [13, с. 105]. Ученым подмечено, что Всеобщая декмарация прав человека 1948 г. устанавливает возможность ограничения прав и свобод именно в таком ключе. Возможно, различение законодателем правовых дефиниций «ограничение прав и свобод» и “ограничение реализации прав и

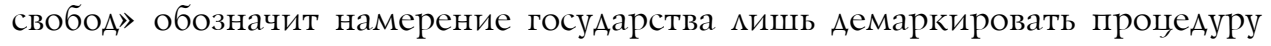
реализации прав и свобод человека и гражданина, и полемика о семантической близости терминов: «отмена», «умамение» и «ограничение» будет переведена в более инертную пиоскость.

Пределы - это обозначение некой грани, за которую нельзя заступить. В условиях признания прав и свобод человека и гражданина высшей ценностью, их ограничение явцяется искцючительной мерой регулирования общественных отношений. Ограничение прав Аолжно быть обусловлено объективными причинами, которые необходимо законодательно обосновать, то есть обозначить фактическое основание и критерии его Аействия. В этом основании должны межкать обстоятельства, при возникновении которых без установления сужающих граниџ пользования правом будет нарушено большее благо, чем ограниченное. Критерии допустимости установления таких граниџ Аолжны искцючать возможность злоупотребления правоприменителем своей вмастью и правом. В связи с этим принџипы ограничения, фактические основания, цени подвергаются глубокому всестороннему научному анализу, ведь обоснованность конституционного ограничения прав и свобод требует законодательного закрепления базовых основ его применения.

Право зиждется на принџипах, под которыми понимаются «исходные, определяющие идеи, положения, установки, которые составцяют нравственную и организационную основу возникновения, развития и функционирования права» [14, с. 4]. Правовое ограничение не домжно быть исключением. «Границы (пределы) свободы кичности, ее автономия опредемяются объективными закономерностями развития общества» [15, с. 132], а правовые принципы, как известно, явмяются объективной категорией, не зависящей от субъективного усмотрения. В ч. 3 ст. 55 Основного Закона закреплено мишь то, что ограничения могут быть применены «в той мере, в какой это необхоАимо» указанным целям (принцип соразмерности). Следовательно, ограничения по своему объему приравниваются к объему угроз конституционному

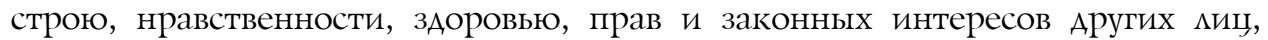
обороны страны и безопасности государства. ОАнако неясно, как определить степень угрозы, чтобы считать ее достаточной Аля применения ограничительного регулирования, каковы должны быть характер и степень ответных ограничений и чем или кем опредемяется эта «мера необходимого». Представцяется, что ответы могут быть сформированы судебной практикой. 
Выявлению правомерности применения ограничения прав и свобод в большей степени способствует деятельность Конституџионного Суда Российской Федерации. Он неоднократно формулировал позиџии в отношении ограничений прав и свобод человека и гражданина, обобщая которые, можно выделить следующие основные критерии допустимости и необходимости:

а) при выявлении законности ограничения необходимо исследовать буквальный смысл соответствующей конститущионной нормы во взаимосвязи с Аругими конституционными нормами и с конкретизирующими ее законодательными актами;

б) ограничения домжны анализироваться с учетом принципов соразмерности (пропорџиональности), Аифференцированности, всеобщего равенства;

в) ограничения должны быть объективно оправданными, обоснованными и преследовать конституционно значимые цеми, чтобы быть допустимыми;

г) ограничения имеют конкретные основания;

А) при установлении ограничений должно соблюдаться соотношение пубАичных и частных интересов [16-18] .

Анализируя перечисленное, можно предположить, что допустимость и необходимость ограничений обосновываются смысловым содержанием конституџионно-правовых установлений, выраженных в нормах законодательства, регулирующего конкретные условия и порядок их применения, в процессе интерпретации которого исследуются основания их применения, соблюдение баланса законных интересов в правовых отношениях между мичностью, обществом и государством, достигаемого при помощи средств адекватных поставленным џелям, распространяющихся, с одной стороны, на всех миџ и граждан, с Аругой - на определенный круг киц, очерченный основанием закрепления ограничения прав и свобод.

Вопрос об основаниях конституционных ограничений имеет первостепенное значение. Часто они смешиваются с цемями ограничений. Между тем основание - это явление, обстоятельство, процесс, явАяющийся поводом к законодательному закреплению возможности ограничения прав и свобод, а цель - это предполагаемый результат, которого стремиться достичь законодатель, посреАством ограничения. Их разАичие подтвержАает и Конституџионный СуА РФ. В деме «Анчугов и ГАадков против России» СуА указал на связь ограничения, предусмотренного ч. 3 ст. 32 Основного Закона с Авумя основаниями: уголовно-правовым и уголовно-исполнительным. Отметим, что они не относятся к конституционно-правовому регулированию - проблема уровня закрепления ограничений также продомжает обсуждаться, они явцяются предметом отраслевого законодательного регулирования. В мюбом случае это основания юридические. К фактическим же основаниям, по нашему мнению, следует относить обстоятельства объективной действительности. К примеру, ограничение права киџа на цичную физическую свободу возможно на основании обвинительного приговора суда (правовое основание), вынесенном по установленному и доказанному факту совершения соответствующего преступкения (фактическое основание). Таким образом, конститущионные ограниче-

16 Bulletin of the Volga Region Institute of Administration • 2019. Vol. 19. № 3 
ния прав и свобод человека и гражданина должны инициироваться фактами нарушения конституционных основ государства, нравственности, прав и свобод человека и гражданина, безопасности и т.А.

Без сомнения, «мюбой запрет (ограничение) должен носить характер предусмотренного законом» [19, с. 54], и его признание требует более детального позитивно-правового закрепления. Поэтому существует острая необходимость как на теоретическом, так и на правоприменительном уровне разрешить конституционные комиизии, касающиеся регулирования ограничения прав и свобод человека и гражданина, к основным из которых, безусловно, относится слеАующее: оПреАеление ПодходОв к толковаНИю поНятия «ограничение прав и свобод человека и гражданина» и пониманию соџиально-правового феномена, межащего в его основе; законодательное закрепление принципов, отражающих взаимосвязь основания и целей ограничения прав и свобод человека и гражданина; определение способов, форм и уровней законодательного закрепления ограничения прав и свобод человека и гражданина; закрепление характерных элементов и признаков ограничения прав и свобод; закрепление определенных границ применения ограничения прав и свобод властными субъектами.

Круг обозначенных вопросов не является исчерпывающим, а мишь платформой, от которой можно оттолкнуться в цемях Аальнейшей юридической интерпретации понятия и пределов конституционного ограничения прав и свобод мичности, а также определения потенџиала его реализации в российском отраслевом законодательстве и практике применения. Безусловно, развитие Аискуссии в исследуемой области позволит конкретизировать сферы действия конституционного правоограничения и создать соответствующие механизмы его воплощения, адекватно отвечающие современным реалиям общественной жизни и государственного устройства, способные защитить человека и гражданина вне зависимости от его правового статуса от зцоупотребцений властью и противоправных посягатецьств со стороны субъектов (как индивидуальных так и комлективных) размичных правовых отношений.

\section{Библиографический список}

1. Эбзеев Б.С. Конституционный правопорядок и основные права: юридическая природа и особенности государственной защиты (о методологии научного поиска) // Государство и право. 2016. № 10. С. 5-18.

2. Пресняков М.В. Конституционно-правовая сущность естественных прав: проблемы позитивного закрепления // Современное право. 2014. № 10. С. 21-25.

3. Матузов Н.И. Теория и практика прав человека в России // Известия высших учебных заведений. Правоведение. 1998. № 4 (223). С. 22-35.

4. Кистяковский Б.А. Социальные науки и право. Очерки по методологии социальных наук и общей теории права. М., 1916.

5. Толковый словарь живого великорусского языка / В.И. Даль: в 4 т. Т. 4: Р-Я. М., 2006.

6. Конституция Российской Федерации // С3 РФ. 2014. № 31. Ст. 4398.

7. Хабриева Т.Я., Чиркин В.Е. Социальная справедливость (некоторые конституционные вопросы) // Общественные науки и современность. 2017. № 3. С. 5-14. 
8. Авакьян C.A. Свобода общественного мнения и конституционно-правовые гарантии ее осуществления // Вестник Московского университета. Сер. 11: Право. 2012. № 6. С. 3-22. № 3.

9. Ильин И.А. Общее учение о праве и государстве (фрагменты) // Правоведение. 1992.

10. Хессе $К$. Основы конституционного права ФРГ / пер. с нем. Е.А. Сидорова; под ред. Н.А. Сидорова (вступ. ст.). М., 1981.

11. Малько A.B. Стимулы и ограничения в праве: теоретико-информационный аспект. 3-е изд., доп. и перераб. Berlin: Lap Lambert Academic Publisching, 2011.

12. Лапаева В.В. Проблема ограничения прав и свобод человека и гражданина в Конституции РФ (опыт доктринального осмысления) // Журнал российского права. 2005. № 7. C. $13-24$.

13. Краснов М.А. Ограничение прав человека или поиск их естественных пределов? // Право. 2009. № 2. С. 103-115.

14. Байтин М.И. О принципах и функциях права: новые моменты // Известия высших учебных заведений. Правоведение. 2000. № 3 (230). С. 4-16.

15. Лебедев B.A. Конституционные основы ограничений прав и свобод человека и гражданина // Lex Russica. 2017. № 1 (122). C. 130-139.

16. Постановление Конституционного Суда РФ от 29 мая 2018 г. № 21-П по делу о проверке конституционности пунктов 1 и 3 статьи 8 Федерального закона «О правовом положении иностранных граждан в Российской Федерации» в связи с жалобой гражданина Социалистической Республики Вьетнам Нгуен Чонг Хая // Вестник Конституционного Суда РФ. 2018. № 5.

17. Постановление Конституционного Суда РФ от 1 марта 2017 г. № 3-П по делу о проверке конституционности части 5 статьи 43 Федерального закона «О полиции» в связи с жалобами граждан В.А. Семенова и Н.В. Шмакова // Вестник Конституционного Суда РФ. 2017. № 3.

18. Постановление Конституционного Суда РФ от 19 апреля 2016 г. № 12-П по делу о разрешении вопроса о возможности исполнения в соответствии с Конституцией Российской Федерации постановления Европейского Суда по правам человека от 4 июля 2013 г. по делу «Анчугов и Гладков против России» в связи с запросом Министерства юстиции Российской Федерации // Вестник Конституционного Суда РФ. 2016. № 5.

19. Бородин В.В., Крусс В.И. Некоторые философско-правовые аспекты проблемы злоупотребления правами и свободами человека // Известия высших учебных заведений. Правоведение. 2002. № 6 (245). С. 34-56. 